\title{
IMPROVING SEED SPACING UNIFORMITY of PRECISION VEGETABLE PLANTERS
}

\author{
M. C. Siemens, R. R. Gayler
}

\begin{abstract}
Equidistant, uniform seed placement is important in lettuce production as seeds are densely planted within the row, typically only about $5 \mathrm{~cm}$ apart. When seeds are sown too close together, it is time consuming to thin seedlings to the desired plant spacing of 20 to $30 \mathrm{~cm}$ by hand and very difficult to do mechanically. The overall goal of the project was to improve lettuce seed placement accuracy and reduce the percentage of seeds spaced closely together. Specific objectives were: 1) to compare vacuum and belt-type planters to determine which style of planter provides better planting performance, 2) to evaluate belt planter seeding performance with different types of furrow openers, and 3) to develop practical modifications for vacuum planters to improve lettuce seed placement accuracy. Three vacuum planter configurations, an unmodified and two reduced seed drop height designs and a belt planter equipped with two types of furrow openers were tested in situ with pelleted lettuce seed at four travel speeds ranging from 1.6 to $4.0 \mathrm{kph}$. Belt planter performance was significantly better than that of the vacuum planter. Vacuum and belt planters both provided acceptable levels of performance at speeds below $2.4 \mathrm{kph}$, but at higher speeds, seed placement accuracy declined rapidly. No differences in planter performance were found between the two belt planter configurations tested. The mid-level drop height vacuum planter configuration had significantly better seed placement precision and fewer closely spaced seed spacings as compared to the unmodified vacuum planter. These findings illustrate the significant effect planter type, travel speed, and drop height have on planter performance. They also contradict the common perception that vacuum planters deliver seed more precisely and with fewer closely-spaced seeds as compared to belt planters. Further study is needed to determine the extent to which planter performance affects hand thinning labor costs, automated machine performance, final plant stand uniformity, and crop yield.
\end{abstract}

Keywords. Accuracy, Belt planters, Lettuce, Planters, Precision, Seed spacing, Thinning, Uniformity, Vacuum planters.

A lthough vegetable seeds are typically sown with precision planters, seed placement uniformity is surprisingly poor. Research studies with raw and pelleted seeds have shown that typically, only about two-thirds of the seeds planted with precision planters are placed within $3.8 \mathrm{~cm}$ of the target spacing (Kachman and Smith, 1995; Parish and Bracy, 1998; Bracy et al., 1999; Panning et al., 2000; Bracy and Parish, 2003). This level of precision can be problematic for crops such as iceberg and romaine lettuce (Latuca sativa L.) where seed is typically densely sown at roughly $5 \mathrm{~cm}$ spacing to ensure adequate stand establishment. Following germination, the crop is thinned to the desired final plant spacing of 20 to 30 $\mathrm{cm}$ to optimize head size and quality. Conventionally, this task is performed manually by workers equipped with hand

Submitted for review in December 2015 as manuscript number MS 11721; approved for publication by the Machinery Systems Community of ASABE in May 2016. Presented at the 2015 ASABE Annual Meeting as Paper No. 152190060.

Reference to a product or company is for specific information only and does not endorse or recommend that product or company to the exclusion of others that may be suitable.

The authors are Mark C. Siemens, ASABE Member, Associate Specialist and Professor, and Ronald R. Gayler, Staff Technician, Department of Agricultural and Biosystems Engineering, University of Arizona, Tucson, Arizona. Corresponding author: Mark C. Siemens, 6425 W. $8^{\text {th }}$ St., Yuma, AZ; phone: 928-782-3836; e-mail: siemens@cals.arizona.edu. hoes. When plants are spaced close together, extra time and care is required to remove the excess seedlings without injuring the "saved" crop plant. In 2012, automated machines for thinning lettuce were commercialized (Siemens, 2014). These machines utilize a camera-based machine vision system to detect plants and an herbicidal spray to thin unwanted seedlings. Their adoption has been limited, however, due in part to poor performance when plants are irregularly spaced. One problem is that the image processing algorithms used by these machines cannot identify individual seedlings without visible separation between leaves on adjacent plants. Thus, when closely spaced plants have overlapping leaves, the system identifies the two plants as a single plant and both seedlings are left in field. This results in increased labor costs during the subsequent hand weeding operation where weeds and any remaining closely spaced crop plants are removed.

A further drawback of closely spaced plants is the risk of herbicidal spray drifting onto the saved crop plant. Typically, a buffer distance of at least $1.0 \mathrm{~cm}$ is required between leaf edges of adjacent plants to prevent crop injury. Since lettuce is thinned when plants are about $2.0 \mathrm{~cm}$ in diameter, plant spacing must be greater than $3.0 \mathrm{~cm}$ in order for automated machines to operate properly.

In lettuce production, the two most common types of precision planters used are belt and vacuum planters. The basic design of these planters hasn't changed significantly 
since their commercialization over 65 and 30 years ago, respectively (David Fountain, Solex Corp., personal communication, 11 February 2014). There are a limited number of reports in the literature about attempts to improve the performance of these or other types of precision planters used for vegetable production (Parish et al., 1991). Most research has concentrated on reducing seed drop height, modifying seed tubes, and/or comparing planter types and configurations to determine which is best. Parish and Bracy (2003) hypothesized that planter performance would be improved with lower seed drop height and equipped a Gaspardo vacuum planter with two types of seed tubes that reduced seed drop height from 17.8 to $2.5 \mathrm{~cm}$. Seed placement uniformity, however, was degraded when either of the seed tubes was added, due presumably to erratic seed trajectory patterns caused by seeds colliding with and bouncing off the tubes. Panning et al. (2000) evaluated a precision planter equipped with custom and commercially available seed delivery tubes in the field and laboratory studies with pelleted sugar beet seed. Use of the custom seed tube significantly improved performance in the lab where seed was deposited onto a greased track which prevented the seed from bouncing or rolling. When tested in the field, however, seeding accuracy of the custom seed tube configuration decreased by more than $33 \%$ and was comparable to that of the standard seed tube. The authors concluded that laboratory test methods cannot be used to predict planter seed spacing uniformity in the field since seed bounce and roll significantly affects final seed placement. Bracy and Parish (1998) evaluated a belt and two vacuum-type planters for seeding uniformity with five vegetable crops. They found that overall the belt planter provided more uniform and precise metering than either of the vacuum planters. Bracy et al. (1999) reported similar findings in an experiment with cabbage seed. Little work has been reported on the performance of precision planters with lettuce seed or efforts to improve their accuracy. This research addresses this shortcoming.

The goal of this project is to compare vacuum- and belttype planters to determine which style of planter provides better lettuce seed spacing uniformity and fewer closely spaced seeds. A further goal is to evaluate belt planter seeding performance with two types of furrow openers. A final object is to develop practical modifications for vacuum-type planters to improve lettuce seed placement accuracy and reduce the percentage of seeds spaced closely together to levels where automated thinning machines can be operated successfully.

\section{MATERIALS AND METHODS}

In the experiment, a Stanhay 785 Singulaire planter (Stanhay Webb Ltd., Bourne, UK) was used. Three different seed metering unit configurations, an unmodified unit and two modified units were tested. The unmodified configuration, shown in figure 1a, will be referred to hereafter as "Vac-Conv." The first modified unit had the standard furrow opener replaced with a custom designed opener that reduced the seed release height from 8.4 to $6.6 \mathrm{~cm}$ (fig. 1b). Henceforth, this unit will be referred to as the "Mid-Ht" vacuum planter. The second modified unit tested had a seed drop height of $4.8 \mathrm{~cm}$ (fig. 1c). To obtain such a low drop height, the bottom of the planter's metering unit casting was cut off and milled flat. A custom made furrow opener was then attached to the bottom of the unit. This configuration was termed "Low-Ht." The geometry of the two custom furrow openers was similar to that of the conventional opener, but all differed slightly from each other due to design constraints and fabrication limitations. One difference was that the conventional opener had a V-shaped bottom edge whereas the custom openers were square. Another difference was that the distance between the front of the runner and seed release point for the Low-Ht opener was $3.8 \mathrm{~cm}$ greater than that of the Vac-Conv and Mid-Ht openers. The distance between the end of the runner and the seed release point varied little between openers, less than $0.6 \mathrm{~cm}$.

Also, the Vac-Conv and Mid-Ht openers were arc shaped while the Low-Ht opener was rectangular with an arced leading edge (fig. 1a, b, c). The Vac-Conv and MidHt configurations were tested using the same Stanhay Singulaire metering unit. The Low-Ht configuration utilized a separate, but identical model, Stanhay Singulaire metering box. All units were tested using the same 72-hole seed plate. Hole diameter was $2.0 \mathrm{~mm}$.

Two Stanhay 870 belt-type planter configurations were evaluated. These were the standard unit with no modifications (Belt-Conv) (fig. 1d) and the standard unit equipped with a Sutton Ag Enterprises Standard 303 opener (Sutton Ag Enterprises, Inc., Salinas, Calif.) (Belt-Sutton $\mathrm{Ag}$ ) (fig. 1e). Both configurations were tested using the same metering box. The main difference between the two openers was that the leading edge of the conventional opener had hard, linear angles, while the Sutton $\mathrm{Ag}$ Enterprises, Inc. opener had a curved geometry. Also, the seed drop height of the conventional opener was $4.8 \mathrm{~cm}$ and substantially lower than that of the Sutton $\mathrm{Ag}$ Enterprises Inc. opener which released seed $6.4 \mathrm{~cm}$ above the soil surface. Both configurations used a 60 hole, Stanhay ribbed belt, hole punch 13.0 with a S-2 spring base and a type A choke plate. The 13.0 hole punch designation corresponds to belt holes formed using a 13/64 in. (0.52 $\mathrm{cm}$ ) diameter punch.

The seeding units were mounted on a two-row bed shaper, with the vacuum units positioned over one bed shaper and the belt planter carriage on the other. Power to the metering boxes was provided by a Stanhay ground drive system. Ground drive gearing was adjusted according to the manufacturer's spacing chart to provide a seed spacing of $5.1 \mathrm{~cm}$. Furrow opener height was set so that sowing depth was approximately $0.6 \mathrm{~cm}$. The lettuce seed used in the study was a pelleted, Romaine variety "Rubicon" with a seed count of 5,886 seeds per kilogram. The belt planter recommendations for the seed, which indicates seed size and material property characteristics, were to use a Stanhay ribbed belt, hole punch 13.0 with a S-2 spring base and a type A choke plate. A vacuum (Model 86MT600C, Shop-Vac, Williamsport, Pa.) was 

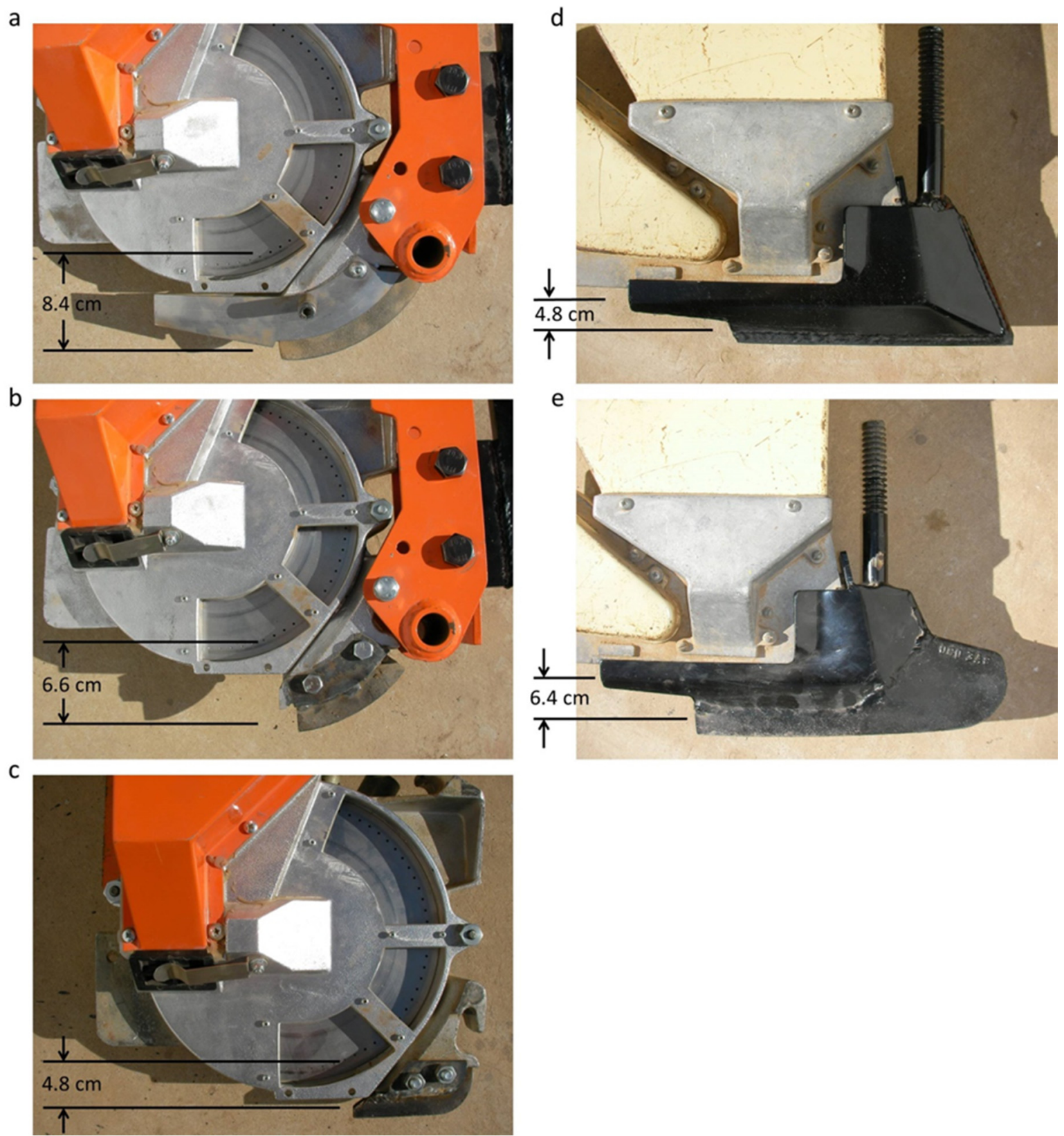

Figure 1. Planter configurations evaluated included a Stanhay 785 Singulaire vacuum metering unit equipped with (a) conventional, (b) midlevel seed drop height, (c) low-level seed drop height furrow openers and a Stanhay 870 belt planter equipped with (d) conventional, and (e) Sutton Ag Enterprises Standard 303 furrow openers. Measurements shown indicate seed drop height.

used to provide $3.5 \mathrm{kPa}$ of vacuum to the vacuum planters. Vacuum pressure was held constant for all tests. Each planter configuration was tested at four travel speeds: 1.6, $2.4,3.2$, and $4.0 \mathrm{kph}$. The experiment was conducted at the University of Arizona's Yuma Agricultural Center, Yuma, Arizona. Soil type at the site was a Gadsden Clay. Experimental design was a two factor, split plot, completely randomized complete block with 3 replications and 20 treatments. The factors were travel speed and planter configuration. To facilitate conducting the experiment, each planter configuration was operated at all four travels speeds before switching to the next planter. Prior to conducting the experiment, the soil at the test site was tilled until its consistency was powder like and then listed to form beds. Bed spacing was $1.1 \mathrm{~m}$ and plot size was one row wide by $7.6 \mathrm{~m}$ long. After sowing, 120 consecutive seed spacing measurements were made by using a putty knife to locate seed in situ, pre-emergence and a tape measurer to record the distance between the seeds. Measurements were recorded to the nearest $0.5 \mathrm{~cm}$.

The four criteria used to compare planter performance were based on ISO Standard 7256/1 (International Organization for Standardization, 1984), measures listed by Kachman and Smith (1995), Panning et al. (2000), and Smith and Kocher (2008) and the aims of this study. These included difficult to thin spacings (Diff-to-Thin), precise spacings (Precise), skipped spacings (Skips), and coefficient of variation of Singulated spacings (Single-COV) (table 1). 
According to Smith and Kocher (2008), these four parameters provide a very complete numerical picture of seed spacing accuracy. To assess cases where two or more seeds are picked up by the metering unit and deposited at the same time, most researchers utilize a multiple index (Mult), defined as the percent of spacings that are less than or equal to one half the target spacing. Diff-to-Thin was used here to quantify these planter errors and to assess the percentage of seed spacings that would result in plant spacings that would be difficult to thin. Here, Diff-to-Thin was defined as the percentage of spacings that have a length less than or equal to $3.0 \mathrm{~cm}$, which is slightly more than half the target spacing of $5.1 \mathrm{~cm}$. This distance was selected since it allows for a $1.0 \mathrm{~cm}$ gap between adjacent, $2.0 \mathrm{~cm}$ diameter plants, a distance necessary for automated thinning machines to thin effectively without injuring crop plants. An acceptable level of Diff-to-Thin spacings was taken to be $6 \%$ as this would not significantly slow down hand crews that weed and remove closely spaced plants after thinning. Precise spacings (Precise) was the percentage of spacings that were within $\pm 1.0 \mathrm{~cm}$ of the target spacing. Other researchers have defined Precise as the percentage of spacings $\pm 1.5 \mathrm{~cm}$ of the target spacing (Panning et al., 2000; Smith and Kocher 2008). A tighter tolerance for Precise was used here because with the narrow target spacing of $5.1 \mathrm{~cm}, 1 \mathrm{~cm}$ represents an error of roughly $20 \%$ in seed placement accuracy and a maximum that was considered acceptable. Singulated spacings (Single) was defined as those spacings with a length between 0.5 and 1.5 times the target spacing. Bracy et al. (1999) used a criterion that more than $85 \%$ of the seed spacings should be Single spacings in order for planter performance to be considered satisfactory. This criterion was established for planters tested in a laboratory environment. Considering that the planters in this study were evaluated in the field and Precise has a tighter tolerance as compared to Single spacings, an acceptable value for Precise was set to $65 \%$ in this study. Skipped spacings (Skips) is the percentage of spacings that are more than 1.5 times the target spacing. This occurs when the metering unit fails to pick up a seed or when adjacent singulated seeds bounce and roll excessively. Single-COV is the coefficient of variation of Single spacings which was defined previously. Single-COV is a much better indicator of the true variation in seed placement uniformity than the coefficient of variation of all spacings as outliers, namely Mult and Skips, are omitted. Although the theoretical upper limit for Single-COV is $50 \%$, a practical upper limit where all spacings are spread uniformly within the target range is $29 \%$ (Kachman and Smith, 1995).

Table 1. Descriptions of criteria used to assess precision planter performance.

\begin{tabular}{llc}
\hline \multicolumn{1}{c}{ Criteria } & \multicolumn{1}{c}{ Description } & $\begin{array}{c}\text { Range } \\
(\mathrm{cm})\end{array}$ \\
\hline Diff-to-Thin & Spacings problematic to thin by machine & $\leq 3$ \\
Precise & Spacings \pm 1 cm of target spacing & \\
Single-COV & Coefficient of variation of Single spacings & $4.1-6.1$ \\
Skips & Spacings $>1.5 \times$ target spacing & $>7.6$ \\
Single & Singulated seed spacings & $2.6-7.6$ \\
\hline [a] Target spacing was $5.1 \mathrm{~cm}$.
\end{tabular}

An ANOVA was performed using SAS (SAS Institute Inc., 2010) to determine statistically significant differences between treatment means. The data were analyzed as a one way factorial design and two separate two-way factorial designs. In the one way ANOVA, the performance of the unmodified vacuum planter was compared with the conventional belt planter configuration. Seed spacing frequency distribution plots of Vac-Conv and Belt-Conv were also used to compare vacuum and belt planter performance. In the first two-way ANOVA, planter performance data were analyzed with belt planter configuration and planter travel speed as the two factors. In the second two-way ANOVA, vacuum planter configuration and planter travel speed were used as the two factors. Since there was significant interaction between planter configuration and travel speed in both two-way ANOVAs, the data were also analyzed independently to examine treatment effects.

\section{RESULTS}

\section{Conventional Vacuum and Belt Planter PERFORMANCE}

Overall, the data clearly showed that the performance of the belt planter was significantly better than that of the vacuum planters. Performance data for Vac-Conv and BeltConv averaged over all test speeds is shown in figure 2. The Belt-Conv configuration had significantly better seed placement accuracy (Precise), fewer skips (Skips) and lower seed placement variability (Single-COV) as compared to Vac-Conv. The percentage of spacings that are problematic for automated thinners (Diff-to-Thin), however were not significantly different between the two configurations. This result was confounded by the significant interaction between planter configuration and travel speed. The superior performance of Belt-Conv is more clearly shown in figure 3 where frequency distribution plots of seed spacing measurements are plotted for each planter configuration at each of the travel speeds tested. At $1.6 \mathrm{kph}$, Belt-Conv had virtually no Diff-to-Thin spacings $(\leq 3 \mathrm{~cm}$ in figure) while the percentage for ConvVac was $5.3 \%$. Further, the percentage of Precise spacings

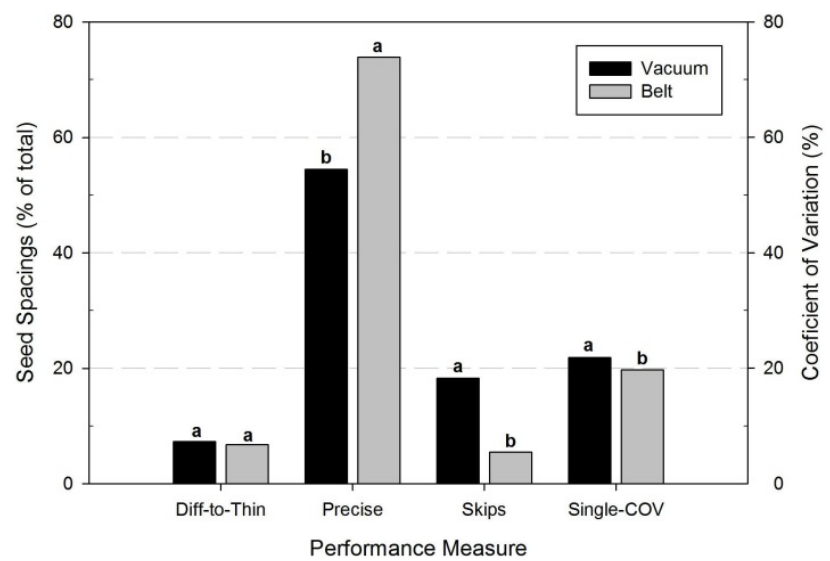

Figure 2. Seeding performance of conventional vacuum and belt planters averaged over four travel speeds, 1.6, 2.4, 3.2, and $4.0 \mathrm{kph}$, in field studies with lettuce seed. 


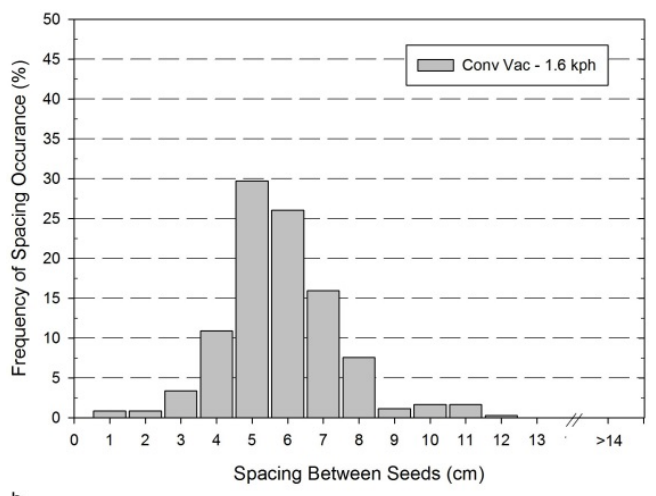

b

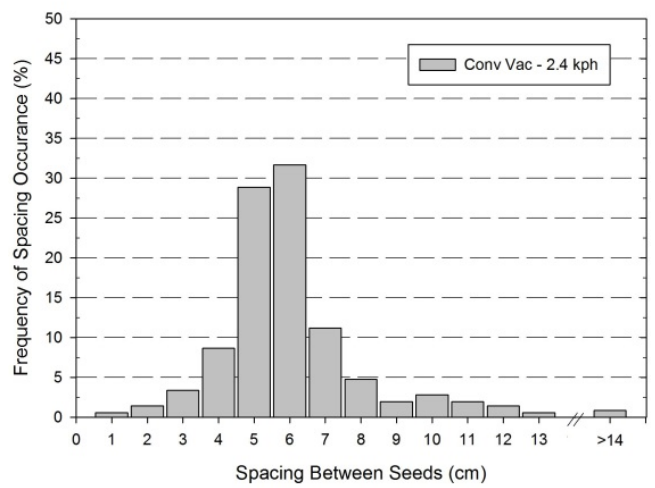

c
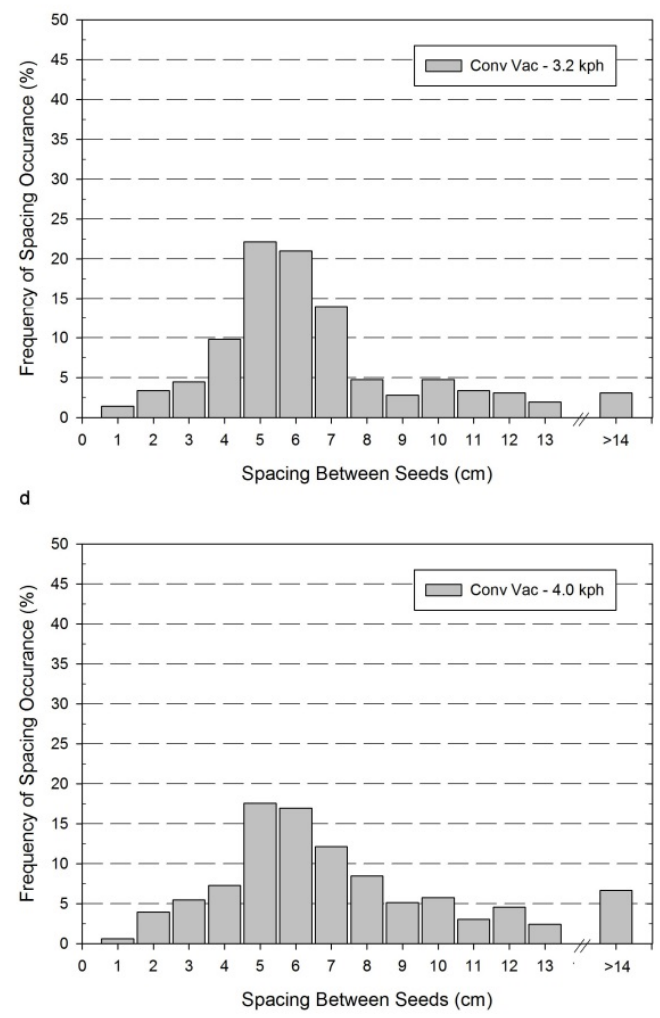
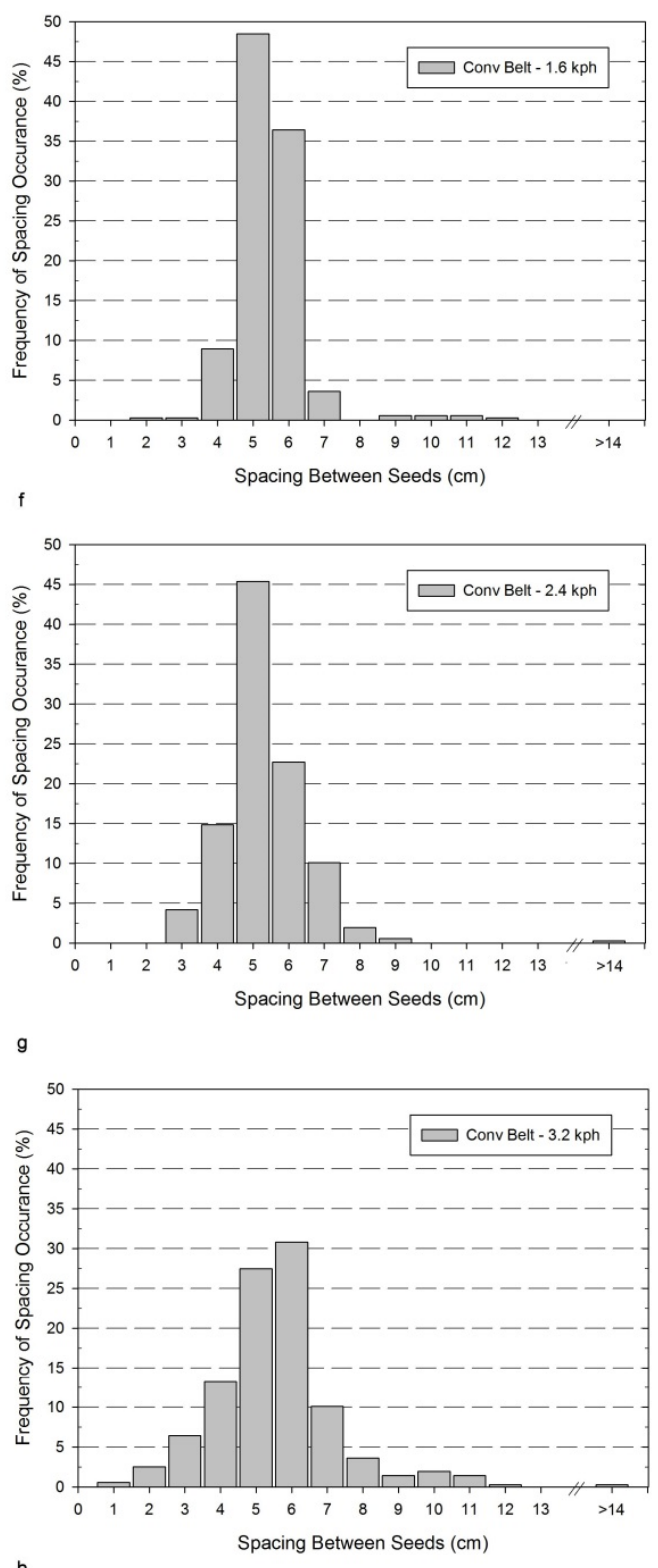

h

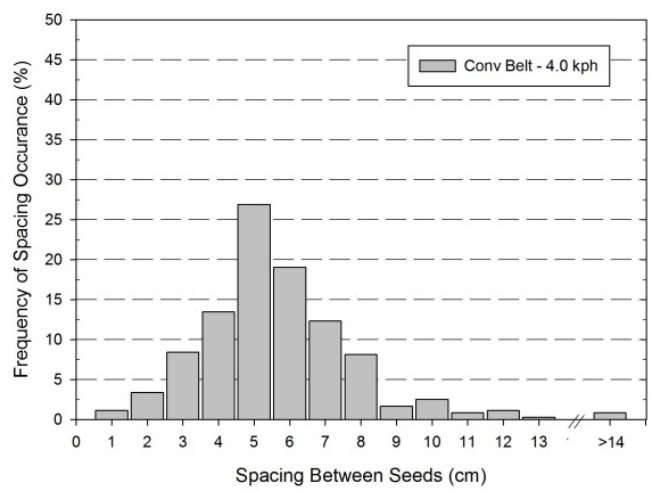

Figure 3. Seed spacing frequency distribution of a conventional vacuum planter operating at (a) $1.6 \mathrm{kph}$, (b) $2.4 \mathrm{kph}$, (c) $3.2 \mathrm{kph}$, (d) $4.0 \mathrm{kph}$, and a conventional belt planter operating at (e) $1.6 \mathrm{kph}$, (f) $2.4 \mathrm{kph},(\mathrm{g}) 3.2 \mathrm{kph}$, (h) $4.0 \mathrm{kph}$ in field studies with lettuce seed. 
for Belt-Conv was $93 \%$ and pointedly higher than VacConv at $64 \%$ (data not shown). These results are comparable to those of Bracy et al. (1999) who found that the percentage of singulated spacings, defined as spacings within $\pm 3.6 \mathrm{~cm}$ of target spacing, was over $90 \%$ with a Stanhay belt planter and less than $41 \%$ with a precision vacuum planter when tested with cabbage seed at a travel speed of $2.4 \mathrm{kph}$. Spacing distribution patterns were visually similar for Belt-Conv at $3.2 \mathrm{kph}$ and Vac-Conv at $2.4 \mathrm{kph}$. This result is significant in that it implies that belt planters can be operated at speeds 33\% faster than vacuum planters with similar seed spacing accuracy.

The plots also show that as speed increases, seed spacing becomes much more variable as indicated by the flatter frequency distribution patterns. A logical explanation for this is that since the forward speed of the planter was higher than the rearward velocity of the seed as it exited the planter, as travel speed increased, seed bounce and roll also increased causing more seed spacing variability. Equipment manufacturers have recognized this effect and have addressed the issue by developing planters for row crops that release seed with rearward velocities equal to planter travel speeds (Dobberstein, 2015).

A plausible explanation for the difference in performance between the two planter configurations is the way in which singulated seed is released from each planter. Belt planters release seed when the hole carrying the seed passes an opening in the bottom of the planter, in essence it is released freely with a horizontal velocity. Vacuum planters, on the other hand, release seed when the seed passes the vacuum "cut-off" point where the pressure differential holding the seed to the seed plate is eliminated. Since the cut-off point is not located at the bottom of the seed plate, seed is released with a velocity that has both the horizontal and vertical components. In test stand observations with Vac-Conv, the angle that seed was released varied continuously and by as much as roughly $10^{\circ}$ as the unit operated. This variation, coupled with its high drop height, could explain the relatively poor seed placement precision of vacuum planters. This hypothesis is supported by the findings of other researchers who also found seed placement accuracy of vacuum planters to be significantly worse than that of belt planters (Parish et al., 1991; Bracy and Parish, 1998; Bracy et al., 1999; Bracy and Parish, 2001). In these studies, seeds were deposited on a greased board which prevented seeds from bouncing and rolling. Therefore, the only reason for the differences found in seed placement precision was due to variations in the way seed is released from each type of planter.

\section{Performance of Belt Planter with Two Types of FURROW OPENERS}

The performance of the two belt planter configurations when averaged across all travels speeds was virtually identical and no significant differences between the two units were found (fig. 4). For both planter configurations, speed had a significant negative effect on performance. This can be seen clearly in figure 5 where the performance of both configurations is plotted for each travel speed. Planting performance was excellent at $1.6 \mathrm{kph}$ where the

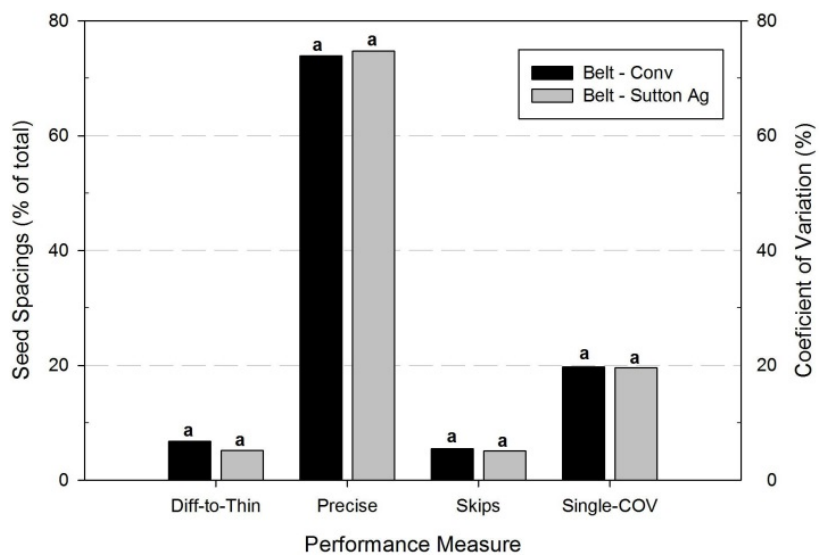

Figure 4. Seeding performance of a conventional belt planter equipped with a (1) conventional and (2) Sutton Ag Enterprises Standard 303 furrow opener averaged over four travel speeds, 1.6, 2.4, 3.2, and $4.0 \mathrm{kph}$, in field studies with lettuce seed.

percentage of Precise spacings was more than $90 \%$ and Diff-to-Thin and Skips spacings were less than $2 \%$. Seed placement accuracy at $2.4 \mathrm{kph}$ was also very good with Precise values exceeding $73 \%$ for both configurations, however Diff-to-Thin values increased to the maximum acceptable value of $6 \%$. When speed was increased to $3.2 \mathrm{kph}$, planter performance declined significantly and Diff-to-Thin spacings increased to unacceptable levels of $9 \%$. At the highest test speed of $4.0 \mathrm{kph}$, seed placement accuracy continued to decline for the Belt-Conv configuration; however the reverse was true for the BeltSutton Ag configuration.

This result could not be logically explained and could perhaps be due to an undetected procedural error that occurred while conducting the experiment such as operating at an incorrect travel speed. These data suggest that operating speeds for belt planters be kept to around $2.4 \mathrm{kph}$ or lower to obtain best performance and acceptable levels of Diff-to-Thin spacings for good automated thinning machine performance.

\section{Peformance OF UNMOdified ANd Modified VACUUM Planters}

Performance results of the three vacuum planter configurations are shown in figure 6. Overall, when averaged across all four travels speeds, performance was considered poor with less than $60 \%$ of the seeds placed within $\pm 1 \mathrm{~cm}$ of the target location (Precise spacings). This level of accuracy, however, was not unexpected as Smith et al. (2003) found that vacuum planter precision, defined as seeds spaced within $\pm 1.5 \mathrm{~cm}$ of the target location, ranged between 52 and 61\%. Figure 6 also shows that planting performance of the Mid-Ht configuration was significantly better than that of Vac-Conv. The unit had fewer Diff-to-Thin spacings, a higher percentage of Precise spacings and a lower Single-COV. The performance of the Low-Ht configuration was similar to the Vac-Conv. As compared to Mid-Ht, Low-Ht had fewer Skips, but significantly more Diff-to-Thin spacings and a higher Single-COV. A clear explanation for why the Low-Ht configuration did not also perform better than the Vac- 

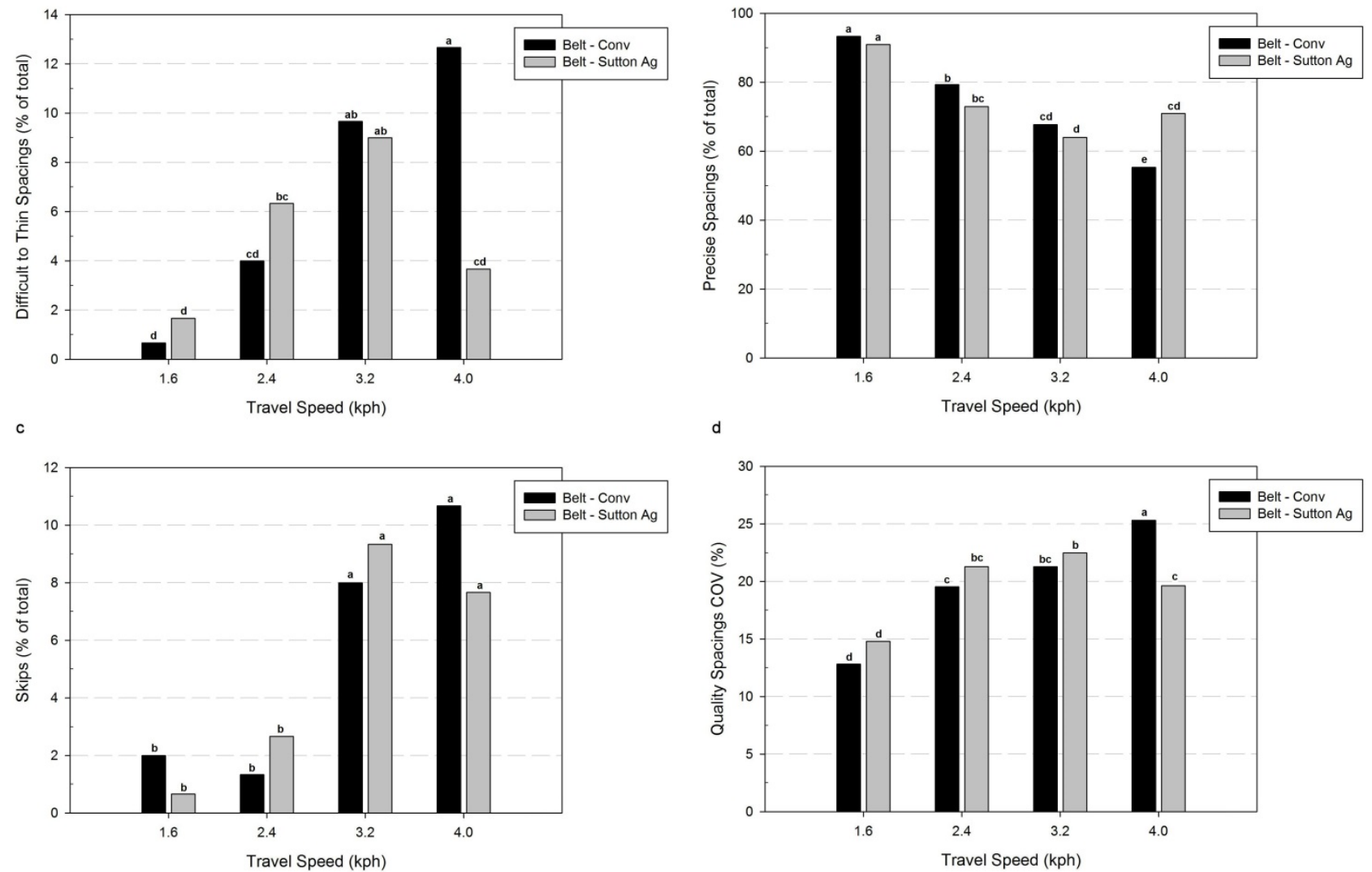

Figure 5. Seeding performance of a conventional belt planter equipped with a conventional and Sutton Ag Enterprises Standard 303 furrow openers in field studies with lettuce seed. Performance measures were (a) difficult to thin spacings, (b) precise spacings, (c) skips, and (d) the coefficient of variation (COV) of singulated spacings.

Conv and had poorer seed placement accuracy than the Mid-Ht could not be formulated. One possible explanation is that the furrow opener geometries were slightly different between the Low-Ht (rectangular with an arced shaped leading edge) and Mid-Ht (arc shaped) configurations (fig. 1b, c). These dissimilarities could result in different seed furrow conditions, which would affect seed placement accuracy. No data, however, was recorded to substantiate this theory and differences were not visually obvious. Another explanation is that due to differences in drop

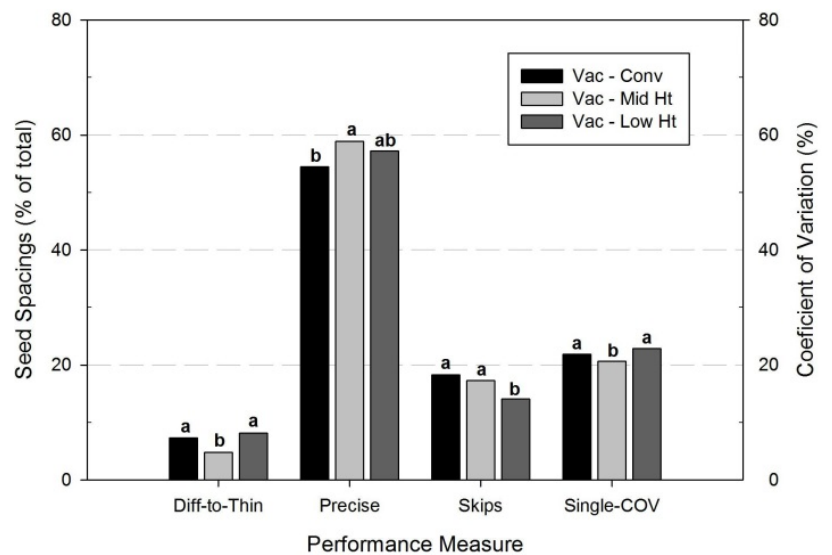

Figure 6. Seeding performance of a conventional and two modified vacuum planter configurations averaged over four travel speeds, 1.6, 2.4, 3.2, and $4.0 \mathrm{kph}$, in field studies with lettuce seed. height, the time it took seed to fall to the soil surface was different for each planter configuration and that perhaps there was some interaction between the timing of when the seed encounters the soil surface and when the furrow closes that affected seed bounce and roll and therefore seed spacing accuracy. Further study on the interactions of drop height, furrow opener design and soil characteristics at the time of seeding are needed to better understand this unexpected result.

The performance of each vacuum planter configuration at each travel speed is shown in figure 7. The figure shows the performance of the Mid-Ht configuration was not as negatively affected by increases in travel speed as the other two configurations and in general had the best performance. As speed increased, Diff-to-Thin spacings for the Vac-Conv and Low-Ht configurations increased from about $5 \%$ to over $10 \%$, while Mid-Ht Diff-to-Thin spacings remained relatively constant at about $5 \%$. At all speeds, Diff-to-Thin values for the Mid-Ht configuration were below the established threshold of $6 \%$. Single-COV for the Mid-Ht planter was also consistently lower than Vac-Conv and Low-Ht, particularly at high travel speeds, indicating that seed spacing was less variable with this configuration. These results indicate the potential to improve vacuum planter performance by reducing drop height. A clear explanation for why the Low-Ht configuration did not also improve planter precision could not be formulated and possible explanations for this result were described 

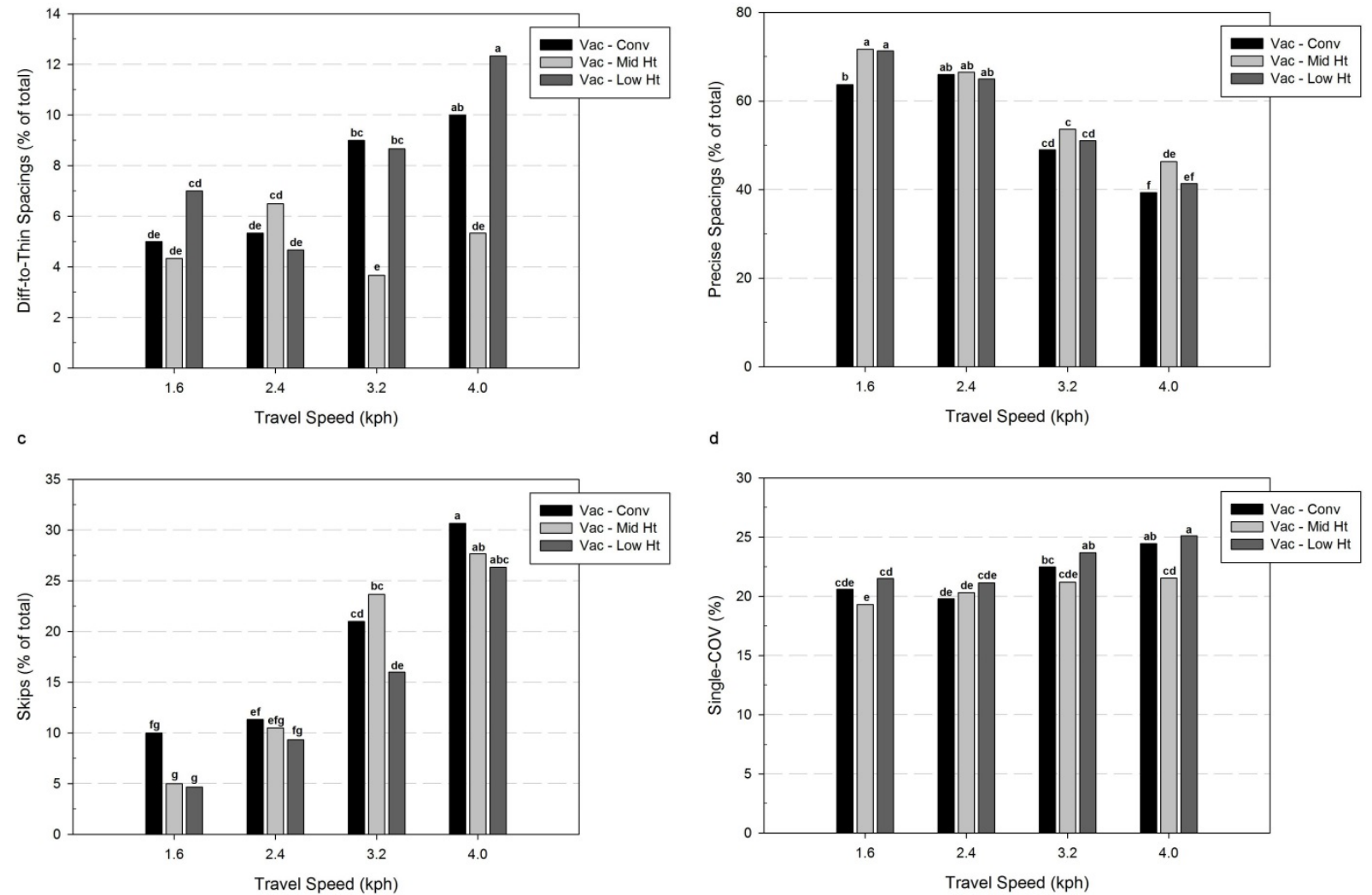

Figure 7. Seeding performance of a conventional and two modified vacuum planter configurations in field studies with lettuce seed. Performance measures were (a) difficult to thin spacings, (b) precise spacings, (c) skips, and (d) the coefficient of variation (COV) of singulated spacings.

previously. The value of Precise was generally constant at about $67 \%$ for all configurations at travel speeds of 1.6 and $2.4 \mathrm{kph}$, but then declined to averages of $51 \%$ and $42 \%$ at 3.2 and $4.0 \mathrm{kph}$, respectively. These findings suggest that there was a travel speed threshold, above which seed bounce and roll have a significant negative affect seed placement precision. The results are supported by those of Panning et al. (2000) who found that vacuum planter Precision, defined as $\pm 1.5 \mathrm{~cm}$ of target spacing, declined from $56 \%$ to $23 \%$ as operating speed increased from 3.2 to $8.0 \mathrm{kph}$. High travel speed also had a significant negative effect on the percentage of Skips. As speed increased from 1.6 to $4.0 \mathrm{kph}$, the percentage of Skips spacings increased from reasonable levels of $5 \%$ to $10 \%$ to very high values of more than $27 \%$. Taken collectively, the data showed that in order for a vacuum planter to have good seed placement accuracy and acceptable levels of precision for use with automated thinning machines, travel speed should be kept to roughly $2.4 \mathrm{kph}$ or lower.

\section{Conclusion}

The conventional belt planter tested provided significantly better seed placement accuracy than the conventional vacuum planter. Additional planter performance studies are needed to support these data as the opposite is commonly believed to be true. Although not examined in this study, a plausible explanation for this result is that the trajectory of seed released from the vacuum planter is much more variable than that of the belt planter. The two belt planter configurations released seed at substantially different heights and had different furrow opener designs. Despite these differences, the performance of the two configurations was very similar suggesting that these design features may have little influence on the seed spacing accuracy of belt planters. Further work in additional soil types is needed to validate this conclusion. Modifications made to a conventional precision vacuum planter showed the potential to improve performance by reducing seed drop height. At the mid-level drop height tested, planter precision and seed spacing variability were significantly improved as compared to the conventional planter which had the highest drop height. An unexpected result was that the planter with the lowest drop height did not also improve performance as compared to the conventional planter. Further study on the effect of drop height on vacuum planter performance is needed. Both types of planters were able to provide acceptable levels of precision and sufficiently low percentages of closely spaced seeds at travel speeds of less than about $2.4 \mathrm{kph}$ for successful operation of automated machines for thinning lettuce. At higher speeds, seed placement precision and spacing uniformity deteriorated quickly to unacceptable levels, presumably due to increased seed bounce and roll. These findings suggest that in order to optimize performance, planters should be designed to release seed 
with a velocity relative to the soil surface that is as close to zero as possible and with a consistent trajectory. This concept has recently been incorporated into commercial row crop planters designed for high travel speeds. Further work is needed to determine the extent to which differences in planter performance affect hand thinning labor costs, automated thinning machine performance, final plant spacing uniformity and crop yield.

\section{ACKNOWLEDGEMENTS}

The Arizona Department of Agriculture, Agricultural Consultation and Training provided partial project funding using Specialty Crop Block Grant funds provided by the USDA, Agricultural Marketing Service. The views or findings presented are the authors and do not necessarily represent those of the Arizona Department of Agriculture, the State of Arizona or the USDA. The authors thank them for their support. The authors would also like to thank Keithly-Williams Seeds, Inc. and Solex Corp. for providing seed, equipment and advice for this study. Their assistance is greatly appreciated. Finally, the authors thank Daniela Lomeli-Anaya for her meticulousness and for her exceptional efforts collecting and recording data.

\section{REFERENCES}

Bracy, R. P., \& Parish, R. L. (1998). Seeding uniformity of precision seeders. HortTechnol., 8(2), 182-185.

Bracy, R. P., \& Parish, R. L. (2001). A comparison of seeding uniformity of agronomic and vegetable seeders. HortTechnol., 11(2), 184-186.

Bracy, R. P., \& Parish, R. L. (2003). Precision vegetable seeders versus agronomic seeders. Louisiana Agric., 46(1), 19.

Bracy, R. P., Parish, R. L., \& McCoy, J. E. (1999). Precision seeder uniformity varies with theoretical spacing. HortTechnol., 9(1), 47-50.
Dobberstein, J. (2015). How fast can you really no-till. No-till Farmer, 44(11). Brookfield, WI: Lessiter Media. Retrieved from https://www.no-tillfarmer.com/articles/5111-how-fast-can-youreally-no-till

International Organization for Standardization. (1984). ISO 7256/1: Sowing equipment - Test methods - Part 1: Single seed drills (precision drills). Geneva, Switzerland: International Organization for Standardization.

Kachman, S. D., \& Smith, J. A. (1995). Alternative measures of accuracy in plant spacing for planters using single seed metering. Trans. ASAE, 38(2), 379-387. http://dx.doi.org/10.13031/2013.27843

Panning, J. W., Kocher, M. F., Smith, J. A., \& Kachman, S. D. (2000). Laboratory and field testing of seed spacing uniformity for sugarbeet planters. Appl. Eng. Agric., 16(1), 7-13. http://dx.doi.org/10.13031/2013.4985

Parish, R. L., \& Bracy, R. P. (1998). Metering nonuniform vegetable seed. HortSci., 33(4), 598.

Parish, R. L., \& Bracy, R. P. (2003). An attempt to improve uniformity of a Gaspardo precision seeder. HortTechnol., 13(1), 100-103.

Parish, R. L., Bergeron, P. E., \& Bracy, R. P. (1991). Comparison of vacuum and belt seeders for vegetable planting. Appl. Eng. Agric., 7(5), 537-540. http://dx.doi.org/10.13031/2013.26264

SAS. (2010). SAS Enterprise Guide. Ver. 4.3. Cary, NC: SAS Institute.

Siemens, M. C. (2014). Robotic weed control. Proc. 66th Annual California Weed Science Society. 66, pp. 76-80. West Sacramento, CA: California Weed Science Society.

Smith, J. A., \& Kocher, M. F. (2008). Evaluate planter meter and seed tube systems for seed spacing performance of confection sunflower seed to improve plant spacing in the field. 2008 National Sunflower Association Workshop. Mandan, ND: National Sunflower Association. Retrieved from http://www.sunflowernsa.com/uploads/research/330/Smith_Plan terMeter_08.pdf

Smith, J., Gatch, R., \& Palm, K. (2003). Plant spacing accuracy of sugarbeet planter models and of options within planter models. Proc. 32nd Biennial Amer. Soc. of Sugar Beet Technologists Meeting, (pp. 97-108). Denver, CO: ASSBT. 